\title{
Lokal ileri evre serviks kanserlerinde yoğunluk ayarlı radyoterapi ve volumetrik ayarlı ark tedavinin dozimetrik karşılaştırılması
}

The dosimetric comparison of intensity modulated radiotherapy and volumetric arc therapy in locally advanced uterine cervix cancer

\author{
Berna Nalbant ${ }^{1} \quad$ Fatma Sert $^{2} \quad$ Emin Tavlayan $^{2} \quad$ Nezahat Olacak $^{2} \quad$ Zeynep Özsaran $^{2}$ \\ ${ }^{1}$ Onkomer Onkoloji Merkezi, Radyasyon Fiziği, Bornova, Türkiye \\ ${ }^{2}$ Ege Üniversitesi Tıp Fakültesi, Radyasyon Onkolojisi Anabilim Dalı, Bornova, Türkiye
}

\section{Öz}

Amaç: Radyokemoterapi lokal ileri evre serviks kanserinin tedavisinde standart yaklaşımdır. Amacımız, serviks kanseri tedavisinde modern tekniklerden yoğunluk ayarlı radyoterapi (YART) ve volumetrik ark terapi (VMAT) tekniklerini dozimetrik olarak karşılaştırmaktır.

Gereç ve Yöntem: Kliniğimizde tedavi edilmiş 10 lokal ileri evre serviks kanseri hastasının bilgisayarlı tomografi (BT)'leri kullanılmıştır. Hastalarda gross tümör hacmi (GTV), klinik tümör hacmi (CTVtm) ve lenf nodları (CTV lenf nodu) ve komşu risk altındaki organları konturlanmıştır. CTVtm ve CTV lenf nodlarına $1.5 \mathrm{~cm}$ sınır verilerek tedavi hacimleri oluşturulmuştur. Total doz $50.4 \mathrm{~Gy}$ olacak şekilde günlük $1.8 \mathrm{~Gy}$ fraksiyon dozu ile tedavi planlamaları yapılmıştır. İki teknik, Doz volüm histogramı, homojenite indeks (HI), konformite indeks (KI), monitör ünit (MU), segment sayısı değerlendirmeleri yapıımıştır.

Bulgular: İnce bağırsak için, $40 \mathrm{~Gy}$ doz alan hacim yüzdeliğinin YART tekniğinde medyan değeri \%14.24 iken, VMAT tekniğinde \%11.28 olarak hesaplanmıştır $(p=0.022)$. VMAT tekniğinde \%12.39 olarak hesaplanan femur başları 30 Gy doz alan hacim değerleri, YART tekniğinde ortanca değeri \%7.80 olarak bulunmuştur ( $p=0.007)$. VMAT tekniği istatistiksel anlamlı seviye kısa sürede tamamlanırken, fraksiyon başına MU değeri anlamlı olarak fazla bulunmuştur. Her iki tedavi tekniğinin de $\mathrm{HI}$ ve $\mathrm{KI}$ değerleri açısından aralarında farklılık gösterilememiştir.

Sonuç: Hasta konforuna ve cihaz performansına açısından VMAT tekniğinde kısa tedavi süresi avantaj olarak görülmektedir. Kliniğimizin mevcut cihaz durumuna göre her iki tedavi modeli de kullanılabilir.

Anahtar Sözcükler: Radyoterapi, yoğunluk ayarlı radyoterapi, serviks kanseri, volumetrik ark terapi, delta-4 fantom.

\begin{abstract}
Aim: The standard treatment approach for locally advanced stage uterine cervix cancer is radio-chemotherapy. New radiotherapy techniques provide appropriate dose distributions with maximum tumor dose and minimum organ at risk doses. We aim to compare intensity modulated radiotherapy (IMRT) and volumetric arc therapy techniques in the cervix cancer treatment.

Materials and Methods: Ten computed tomographies (CT) of treated patients were used. Gross tumor volume (GTV), clinical tumor volume (CTV) both for tumor and lymph nodes and organ at risks were contoured. Treatment volumes were created by adding $1.5 \mathrm{~cm}$ margins to CTV tumor and lymph nodes. Totally 50.4 Gy doses with 1.8 Gy daily fraction were applied. Two techniques were compared in terms of dose volume histograms, homogenity index $(\mathrm{HI})$, conformity Index (Cl), monitory unit (MU) and segment numbers.

Results: For intestines, V40 Gy were $14.24 \%$ and $11.28 \%$ with IMRT and VMAT, respectively ( $p=0.022)$. For femoral heads, V30 Gy were $7.8 \%$ and $12.39 \%$ with IMRT and VMAT, respectively $(p=0.007)$. The duration time of treatment was significantly short but MU value for each fraction was significantly high with VMAT technique. On the other hand, there could not find any difference in terms of $\mathrm{HI}$ and $\mathrm{Cl}$ between two techniques.

Conclusion: The shortness of treatment duration can be seen as an advantage in terms of both patient comfort and machine performance in VMAT technique. IMRT and VMAT can be preferred for the treatment of locally advanced cervix cancer by taking into the conditions of our department.
\end{abstract}

Keywords: Radiotherapy, intensity modulated radiotherapy, cervical cancer, volumetric arc therapy, delta-4 phantom.

Yazışma Adresi: Fatma Sert

Ege Üniversitesi Tıp Fakültesi, Radyasyon Onkolojisi Anabilim

Dalı, Bornova, Türkiye

Makalenin Geliş Tarihi:23.02.2017 Kabul Tarihi: 15.05.2017 


\section{Giriş}

Serviks kanseri, dünyada kadınlarda görülen kanserler arasında 3.sırayı almakta ve tanı anında \%25'ini lokal ileri evre (FIGO evre IIB ve IVA) olgular oluşturmaktadır. Radyokemoterapi lokal ileri evre serviks kanserinin tedavisinde standart yaklaşım olup, radyoterapinin (RT) başarısı eksternal RT ile brakiterapinin birlikte kullanımına, tümörün ve normal dokuların aldığı dozun optimizasyonuna ve toplam tedavi süresine bağlıdır (1). Amaç, lokal kontrol ve sağkalımı artırırken, yan etkileri en aza indirmektir. Günümüzde teknolojik olanaklarla; her bir ışın demetinin kendi içinde yoğunluğu ayarlanarak konvansiyonel ve üç boyutlu RT tekniklerine göre daha uygun doz dağılımıyla tümöre maksimum, risk altındaki organlara minimum doz veren segmental yoğunluk ayarlı radyoterapi (YART) ve onun rotasyonel şekli olan volümetrik ark terapi (VMAT) teknikleri kullanılmaktadır.

Öte yandan, inopere serviks kanserli olgular için dozimetrik avantajlar sağlayan IMRT ve VMAT gibi teknolojik planlama teknikerinin kullanımı günlük rutin pratikte önerilmemektedir. Komşu organ hareketlerin kontrollerini denetlemedeki zorluklar, tümör kitlesinde ciddi küçülmeler ile tedavi alanında oluşacak değişikliklerin yönetimindeki güçlükler bunun en önemli nedeni olarak kabul edilmektedir.

$\mathrm{Bu}$ çalışmada, lokal ileri evre serviks kanseri tanılı olgularda bilgisayarlı tomografi (BT) görüntüleri üzerinden Monaco tedavi planlaması ve Monte Carlo algoritması kullanılarak YART ve VMAT tekniklerinde tedavi planlamalarının, hesaplanan ve ölçülen doz profilleri, gama indeksi değerleri, tedavi süresi, monitör unit (MU) değerleri gibi dozimetrik ölçümler açısından lineer akselatör tedavi cihazı ve Delta 4 fantomu kullanılarak kalite kontrol verilerinin karşılaştırıması amaçlanmaktadır. Çalışmamızda tedavi tekniklerinin hangisinin daha iyi doz dağılımına sahip olduğu, hangisinde kritik organların daha az doz aldığının değerlendirilmesi planlanmaktadır.

\section{Gereç ve Yöntem}

Ekim 2011 - Mart 2012 tarihleri arasında Ege Üniversitesi Tıp Fakültesi Radyasyon Onkolojisi Anabilim Dalı'nda tedavi edilen lokal ileri evre serviks kanseri tanılı 10 hastanın tedavi için elde edilmiş simülasyon BT'leri retrospektif olarak kullanılmıştır. Her hasta için YART ve VMAT tedavi teknikleri kullanılarak iki planlama yapılmıştır. Dozimetrik değerlendirmeler için tüm ölçümler, VMAT ve YART tedavisine uygun olan 6 MV'lik foton enerjisiyle gerçekleştirilmiş ve ölçümler öncesi cihazın mekanik ve dozimetrik kalibrasyonları yapılmıştır.

Mesane 1 litre radyoopak madde su içirilerek (45 dk-1 saat süresince) doldurulmuştur. İmmobilizasyon amacıyla diz-ayak sabitleyici ve boyunluk yardımıyla, hastalar eller göğüste supin pozisyonunda yatırılmıştır. Görüntüler, üst sınır lomber 3.vertebra, alt sınır torakanter minörün $1 \mathrm{~cm}$ altı olarak belirlenmiş $3 \mathrm{~mm}$ 'lik kesitler kullanılarak elde edilmiştir.

Silindirik, 4 bölümlü, $22 \mathrm{~cm}$ çapında, $40 \mathrm{~cm}$ uzunluğunda, 2 ortagonal detektör düzlemine (1069 diyot) sahip olan delta-4 diyot sıralı fantomu YART ve VMAT tedavi planlamaların kalite kontrollerinin değerlendirilmesi için kullanılmıştır (Şekil-1). Delta-4 fantomunda, 3 boyutlu değerlendirme yapılırken gamma indeksi, DTA (distance to agreement, $3 \mathrm{~mm} \% 3$ ) ve doz deviasyon algoritmaları kullanılarak, 3 Boyutlu, 2 Boyutlu, 1 Boyutlu histogramlar, tablolar, hasta yapıları, MLC gibi parametreler yardımıyla ölçülen ve hesaplanan planlar karşılaştırılmıştır. Gantri açılarını ölçmek için inklonometre kullanılmıştır.

Hastalarda gross tümör hacmi (GTV), klinik tümör hacmi (CTVtm) ve lenf nodları (CTV lenf nodu) ve komşu risk altındaki organları (femur başları, rektum, mesane, ince bağırsak) BT kesitlerinde konturlanmıştır. CTV tm ve CTV lenf nodlarına $1.5 \mathrm{~cm}$ sınır verilerek planlanan tedavi volümü (PTV) oluşturulmuştur. Total doz 50.4 Gy olacak şekilde günlük fraksiyon dozu $1.8 \mathrm{~Gy}$ olarak tedavi planlamaları yapılmıştır. YART tekniğinde, 7 karşılıklı olmayan alan kullanılmıştır. PTV'nin büyüklüğü göz önüne alınarak gantri açıları $206^{\circ}-257^{\circ}-315^{\circ}-0^{\circ}-45^{\circ}$ $103^{\circ}-154^{\circ}$ olarak belirlenmiştir. VMAT tekniği için, tek ark $360^{\circ}$ gantri açısı kullanılmıştır. VMAT ve YART tekniği için uygun şablonlar ve parametreler belirlendikten sonra pencil beam algoritması eşliğinde segment şekli optimizasyonu için Monte Carlo algoritması kullanılmıştır. Segment şekli optimizasyonu sonucunda elde edilen Doz volüm histogramları (DVH) değerlendirilmiştir. Her iki teknik için de en uygun DVH, homojenite indeks $(\mathrm{HI}$, tedavi alanındaki maksimum doz ile minimum doz arasındaki fark), konformite indeks (KI, tedavi edilen hacim ile PTV hacminin tamamının kapsanıp kapsanmaması), MU, segment sayısı değerlendirmeleri yapılmıştır. HI dozun homojen dağılıp dağıımadığının değerlendirmesinde, $\mathrm{KI}$ ise tedavi edilen hacim tarafında PTV'nin tam kapsanıp kapsanmadığının değerlendirilmesinde bilgi vere-ceğinden kullanılmıştır. Her iki değer için de ideal olan 1 veya 1'e en yakın değerlerin sağlanmasıdır. Delta-4 fantomu kullanılarak kalite kontrol verileri karşılaştırılmıştır.

\section{Bulgular}

Çalışmamızda lokal ileri serviks kanserli 10 hastanın tedavi planlamasında YART ve VMAT tedavi modelleri uygulanmıştır. International Federation of Gynecology and Obstetrics (FIGO) evreleme sistemine göre hastaların 10'u FIGO evre IIB ve IVA; yaş aralığı 46-78 arasında değişmektedir.

Onaylanan planların, cihazda uygulanan planlarla uyumluluğunun kontrolü gamma indeksi kullanılarak 
yapılmıştır. Tüm hastalarda gamma indeksi $\gamma \leq 1$ den küçük bulunarak ölçülen dozun istenilen sınırlar ( $\leq \% 3)$ içinde olduğu görülmüştür. On hastanın verileri incelenerek yapılan PTV ve kritik organ dozlarının istatistiksel analizinde PTV'nin hedeflenen dozun tamamının (50.4 Gy) en az PTV hacminin \% 95'sini sarması istenmiştir. Bu sağlanamadığı takdirde minimum hedeflenen dozun \%97'sini (47.9 Gy) en az PTV hacminin \% 95'ni kapsaması yeterli kabul edilmiştir. PTV için diğer uygun değerlendirmeler 50.4 Gy'nin \%90'nının (45.4 Gy), PTV hacminin minimum \%95'ini sarması, 50.4 Gy'nin \%93'ünün (46.9 Gy), PTV hacminin minimum \%99'unu sarması; maksimumlarda ise 50.4 Gy'nin \%110'unun (55.4 Gy), PTV hacminin \%20'sinden daha az sarması ve \%115inin (58 Gy) de PTV hacminin minimum \%5'inden az sarması hedeflenerek uygun DVH grafiği elde edilmeye çalışılmıştır.

Komşu riskli organlardan ince bağırsak için, $40 \mathrm{~Gy}$ doz alan hacim yüzdeliğinin YART tekniğinde medyan değeri \%14.24 iken, VMAT tekniğinde \%11.28 olarak hesaplanmıştır $(p=0.022)$. VMAT tekniğinde \%12.39 olarak hesaplanan femur başları $30 \mathrm{~Gy}$ doz alan hacim değerleri, YART tekniğinde ortanca değeri \%7.80 olarak bulunmuştur $(p=0.007)$. Planlamada tanımlanan toplam dozun 50,4 Gy olması nedeni ile her iki femur başının rutinde kullandığımız $50 \mathrm{~Gy}$ doz alan hacimleri çok düşük olarak hesaplandı ve karşılaştırmada herhangi bir farklılık gösterilemedi. Bunun üzerine, düşük doza maruz kalacak femur başı hacimlerinin bu iki teknik ile fazla olacağı göz önüne alınarak 30 Gy doza maruz kalan hacimlerinin değerlendirilmesi kararlaştırıldı. Böylece rotasyoner ark tedavisi (VMAT) ile yoğunluk ayarlı uygulama arasında femur başları açısından daha sağlıklı bir karşılaştırılma yapılabileceği kararına varıldı. Yapılan karşılaştırmada, beklenildiği gibi VMAT tekniğinde femur başlarının 30 Gy doz alan hacimleri YART tekniğine göre anlamlı fazla bulundu.

Büyük bir kısmı PTV içerisinde olan rektum ve mesane karşılaştırmasında rektumun 50 Gy doz alan hacim yüzdeliğinin YART tekniğinde ortanca değeri \%23.78 iken, VMAT tekniğinde \%25.73 olarak hesaplanmıştır $(p=0.646)$. Aynı şekilde mesanenin aynı doz değerinde aldığı hacim yüzdeliğinin YART tekniğindeki medyan değeri \%26.53 iken, VMAT tekniğinde \%24.45 olarak belirlenmiştir ( $p=0.074)$. Her iki ölçümde de istatistiksel anlamlı farklılık saptanmamıştır. Her iki planlama tekniği için doz volüm histogram verilerinin istenen değerleri ve sonuçları Tablo-1'de gösterilmiştir.

$\mathrm{HI}$ ve $\mathrm{KI}$ değerlerinin istatistiksel analizinin değerlendirmesi yapıldığında; PTV'nin HI'i YART tekniğinde ortanca 0.160 iken, VMAT tekniğinde 0.167 $(p=0.445)$; Kl'i ise YART tekniğinde 0.739 iken, VMAT tekniğinde 0.741 olarak saptanmıştır $(p=0.114)$. Her iki tedavi tekniğinin de $\mathrm{HI}$ ve $\mathrm{KI}$ değerleri açısından aralarında farklılık gösterilememiştir. Her iki planlama tekniği için HI ve KI verileri Tablo-2'de gösterilmiştir.

Tablo-1. Her İki Planlama Tekniği İçin Doz Volüm Histogram Verilerinin Özeti.

\begin{tabular}{|c|c|c|c|}
\hline & $\begin{array}{c}\text { Tanımlanan } \\
\text { Kriterler }\end{array}$ & $\begin{array}{c}\text { VMAT } \\
\text { Hacim (\%) }\end{array}$ & $\begin{array}{c}\text { YART } \\
\text { Hacim (\%) }\end{array}$ \\
\hline \multicolumn{4}{|l|}{ PTV } \\
\hline V\%90 & & 99.47 & 99.53 \\
\hline V\%93 & & 98.68 & 98.54 \\
\hline V\%110 & $\leq \% 5-10$ & 16.53 & 13.86 \\
\hline V\%115 & 0 & 0.57 & 0.35 \\
\hline \multicolumn{4}{|c|}{ İnce Bağırsak } \\
\hline V45 & $<150 \mathrm{cc}$ & 11.28 & 14.24 \\
\hline \multicolumn{4}{|c|}{ Femur Başları } \\
\hline V30 & $<\% 10$ & 12.39 & 7.80 \\
\hline V50 & $<\% 5$ & & \\
\hline \multicolumn{4}{|l|}{ Mesane } \\
\hline V50 & $<\% 50$ & 24.45 & 26.53 \\
\hline V45 & $\leq \% 35$ & & \\
\hline \multicolumn{4}{|l|}{ Rektum } \\
\hline V50 & & 25.73 & 23.78 \\
\hline V40 & $<\% 80$ & & \\
\hline
\end{tabular}

Tedavi süreleri ve fraksiyon başına $M U$ değerlerinin istatistiksel analizinde, elde edilen tedavi süreleri YART tekniğinde ortanca değer $14.26 \mathrm{dk}$, VMAT tekniğinde ortanca değer $9.51 \mathrm{dk}(\mathrm{p}=0.005)$ iken; fraksiyon başına MU, VMAT için ortanca değeri 776.8 , YART tekniği için ortanca değeri ise 621.9 olarak bulunmuştur $(p=0.005)$. VMAT tekniği istatistiksel anlamlı seviye kısa sürede tamamlanırken; fraksiyon başına $\mathrm{MU}$ değeri anlamlı olarak fazla bulunmuştur.

Toplam hasta hacminden PTV çıkartılarak elde edilen sağlıklı dokuların (integral doz) $10 \mathrm{~Gy}$ doz alan hacim yüzdeliği incelendiğinde VMAT tekniği için ortanca değer 44.84 iken, YART tekniğinde ortanca değer 44.60 olarak bulunmuştur ( $p=0.575)$. İntegral doz maruziyeti açısından aralarında farklılık gösterilememiştir.

Tablo-2. Planlama Tekniğine Göre Tüm Olguların Homojenite Indexi (HI) ve Conformite Indeksi (Cl) Verileri.

\begin{tabular}{ccccc}
\hline $\begin{array}{c}\text { Hasta } \\
\text { No }\end{array}$ & \multicolumn{2}{c}{ VMAT } & \multicolumn{2}{c}{ YART } \\
\hline & HI & Cl & HI & Cl \\
1 & 0.171 & 0.751 & 0.184 & 0.750 \\
2 & 0.167 & 0.772 & 0.158 & 0.788 \\
3 & 0.169 & 0.731 & 0.173 & 0.700 \\
4 & 0.180 & 0.690 & 0.170 & 0.630 \\
5 & 0.138 & 0.710 & 0.153 & 0.729 \\
6 & 0.168 & 0.810 & 0.150 & 0.770 \\
7 & 0.181 & 0.731 & 0.160 & 0.691 \\
8 & 0.138 & 0.810 & 0.160 & 0.789 \\
9 & 0.124 & 0.760 & 0.151 & 0.780 \\
10 & 0.166 & 0.720 & 0.182 & 0.710 \\
Ortanca & 0.167 & 0.741 & 0.160 & 0.739 \\
\hline VAT:Voln
\end{tabular}

VMAT: Volumetrik ark terapi, YART: Yoğunluk ayarlı radyoterapi. 


\section{Tartışma}

Serviks kanseri, jinekolojik maligniteler arasında sık görülen ve radyokemoterapi ile tedavi başarısı yüksek bir kanser türüdür. Hastaların uzun sağkalımları düşünülerek yaşam kalitesini bozacak yan etkileri engellemek amacıyla dikkatli bir tedavi planlaması gerekmektedir. $\mathrm{Bu}$ amaçla hasta planlamalarında ince bağırsak, femur başları, rektum ve mesane korumaları önem taşımaktadır. Günümüzde yeni kullanılmaya başlanan VMAT tedavi tekniği ile ince bağırsak dozlarında belirgin düşüşler sağlandığı bilinmektedir $(7,10)$. VMAT tekniği ile jinekolojik kanserlerin yanı sıra, prostat, akciğer, baş-boyun kanserlerinin tedavisinde de diğer tekniklere göre daha üstün sonuçlar elde edildiği gösterilmiştir $(25,26)$. Ancak bu teknikler, inopere serviks kanserinde rutin kullanıma geçmemiştir. Burada komşu organ hareketlerinin kontrollerini denetlemedeki zorluklar, tümör kitlesinde ciddi küçülmeler ile tedavi alanında oluşacak değişikliklerin yönetim güçlükleri önemli rol oynamaktadır. Günümüzde VMAT ve YART'nin inopere serviks kanserinde özellikle seçilmiş paraaortik lenf nodu metastazı olan hastalarda veya tedavi sonrası pelvik yinelemeleri olan serviks veya uterus endometrium kanserlerinde tercih edilmesi önerilmektedir.

VMAT tekniği, çok sayıda değişken parametreye sahiptir. $\mathrm{Bu}$ parametrelerin ayrıntılı kontrolleri yapılmazsa (örneğin maksimum doz hızı, MLC hızı gibi) bu özellik dezavantaja dönüşebilir. Dikkatli izlem ve tecrübe önemlidir $(6,30)$. VMAT tekniği, düşük tedavi sürelerinde bile homojen doz dağılımı sağlamaktadır. Bu özelliği hasta konforu sağlaması, klinik yoğunluğu hafifletmesi, organ hareketinin daha az olması ve ikincil kanser risklerini azaltması bakımından önemli bir avantajdır. YART ile kıyaslanarak kliniklerde hangisinin tercih edileceğine karar vermek mümkün olabilir. Uygulamalardaki farklılıklar sonuçları oldukça etkilemektedir. Bazı çalışmalardaki karşılaştırmalarda pek fazla farklılık bulunmazken, bunun aksine bazı çalışmalarda VMAT'ın tartışmasız çok daha iyi bir teknik olduğunu vurgulanmaktadır (7). YART tekniği, alan sayısı, alanların içindeki kritik organların farklı hacimlerde bulunması ve benzer şekilde VMAT tekniğindeki alanların ayarlanamaması farklı sonuçlar elde etmeye neden olmaktadır.

İnce bağırsak, önemli kritik organlardan biridir. Çünkü ince bağırsak dozundaki artış, akut ve geç dönem yan etkileri arttırmaktadır. VMAT tedavi tekniğiyle ince bağırsak dozlarındaki belirgin düşüş, avantaj sağlamaktadır. Beriwal ve ark. (5) çalışmasında, hasta pozisyonları arasında fazla bir fark olmadığı gösterilmiş olsa da, yine bu çalışmalarında kendilerinin de vurguladıkları gibi YART ve VMAT tedavisi uygulanacak olan hastaların, supin pozisyonda tedavi yapılması hem dozimetrik hem de uygulanabilirlik açısından daha iyi sonuçlar vermektedir.

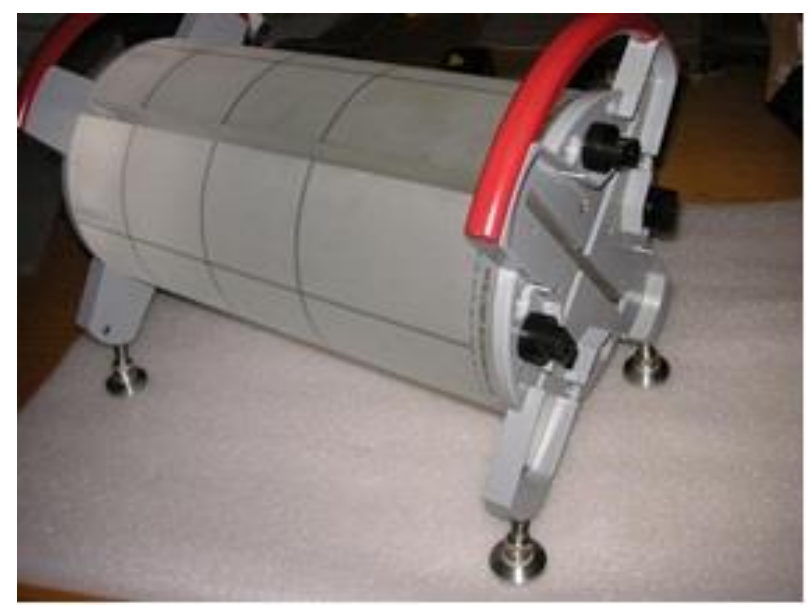

Şekil-1. Delta 4 diyod sıralı fantom görüntüsü.

VMAT ve YART teknikleri, hassas ve gelişmiş dozimetrik ölçüm gerektirir. Delta 4 cihazı, volümetrik ölçümler yaparak rotasyon tedavisine uygun bir biçimde kalite kontrol olanağı sağlamaktadır. Cozzi ve ark. (7), serviks kanserli olguların VMAT ve YART planlarını karşılaştırdığı çalışmalarında, PTV'nin \%5'lik hacmini saran dozun \%95'lik hacmini saran doza farkı kabul edilen HI formülünde VMAT tedavi tekniği kullanıldığında 3.5 $\pm 0.6 \mathrm{~Gy}$, YART tedavi tekniği kullanıldığında ise 4.3 \pm 0.8 Gy değerlerini bulunarak PTV'nin VMAT tedavi tekniğinde daha homojen sarıldığı saptamışlardır $(p=0.11)$ (7). Hedef dozun \% 90'nını saran hacmin PTV hacmine oranı olarak ifade edilen $\mathrm{KI}$ değerlendirmesinde ise VMAT tedavi tekniğinde $1.30 \pm 0.06$, YART tedavi tekniğinde ise $1.41 \pm 0.15$ değeri bulunarak yine VMAT tekniğinde daha iyi hedef sarması olduğu belirlemişlerdir $(p=0.08) \quad$ (7). Çalışmamızda PTV'nin Hl'i, YART tekniğinde ortanca 0.160 iken, VMAT tekniğinde 0.167 $(p=0.445)$; Kl'i ise YART tekniğinde 0.739 iken; VMAT tekniğinde 0.741 olarak bulunmuştur $(p=0.114)$. KI değerleri açısından VMAT planlama tekniğinin sonuçları daha iyi olmasına rağmen anlamlı bir fark saptanmamıştır.

Cozzi ve ark. (7) çalışmasında rektum, mesane ve ince bağırsak dozları VMAT tekniğinde istatistik anlamlı bir farkla daha düşük bulunurken, femur başları dozunda istatistiksel olarak anlamlı bir fark bulunmamış, aynı zamanda sağlıklı doku kıyaslamasında VMAT tekniğinin daha iyi olduğunu gösteren değerler elde etmişlerdir. Kritik organların 40 Gy doz alan hacim yüzdeliklerini her iki teknik için karşılaştırılmasında, rektumun YART tekniğindeki ortalama değeri $\% 78.7 \pm 25.3$ iken, VMAT tekniğinde \%51.5 $\pm 20.7 \quad(p=0.03) ;$ mesanenin YART tekniğindeki ortalama değeri \%62.2 \pm 11.1 iken, VMAT tekniğinde \%47.6 $\pm 12.0(p=0.01)$; ince bağırsağın YART tekniğindeki ortalama değeri \% $13.9 \pm 4.3$ iken, VMAT tekniğinde \%7.5 $\pm 4.6 \quad(p=0.02)$; sağ femurun YART 
tekniğindeki ortalama değeri \%11.0 \pm 10.2 iken, VMAT tekniğinde \%3.5 $\pm 3.1 \quad(p=0.08)$; sol femurun YART

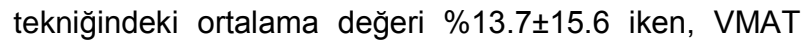
tekniğinde \%6.0 5 5.0 ( $p=0.15)$ bulmuşlardır (7). Fong ve ark. (10), jinekolojik kanserlerde YART, VMAT, 3 boyutlu konformal RT tekniklerini karşılaştırdıkları çalışmanın sonucunda ince bağırsağın $30 \mathrm{~Gy}$ doz alan hacim yüzdeliğinin YART tekniğindeki ortalama değeri $\% 21.9 \pm 5.9$ iken, VMAT tekniğinde $\% 19.5 \pm 3.1$ olup, daha düşük ince bağırsak dozları elde edilmiştir. Diğer kritik organ dozları incelendiğinde, rektumun 40 Gy doz alan hacim yüzdeliğinin YART tekniğindeki ortalama değeri $\% 17.5 \pm 5.0$ iken, VMAT tekniğinde 13.2 \pm 5.0 ; mesanenin $50 \mathrm{~Gy}$ doz alan hacim yüzdeliğinin YART tekniğinde ortalama değeri \%11.5 \pm 4.4 iken, VMAT tekniğinde $\% 9.5 \pm 0.6$ olarak hesaplanmıştır.

Bizim çalışmamızda, risk altındaki organlar için sınırlamalar; ince bağırsakta 40 Gy ve üstü doz alan volüm \%30'dan; femur başlarında 30 Gy ve üstü doz alan volüm \%15'ten; rektumda 50 Gy ve üstü doz alan volüm $\% 35$ 'ten; mesanede 50 Gy ve üstü doz alan volüm \%35'ten daha az olacak şekilde belirlenmiştir $(14,15)$. Yapılan analizde, en önemli riskli organ olan ince bağırsak için 40 Gy doz alan hacim yüzdeliğinin YART tekniğinde ortanca değeri \%14.24 iken, VMAT tekniğinde \%11.28'e kadar düştüğü hesaplanmıştır $(p=0.022)$. İkinci riskli organ femur başları için $30 \mathrm{~Gy} \mathrm{doz}$ alan hacim değerlendirmesinde YART tekniğinde ortanca değeri \%7.80 iken, VMAT tekniğinde daha yüksek olarak \%12.39 değeri hesaplanmıştır $(p=0.007)$. İnce bağırsak ve femur başları için her iki teknik için de bulunan değerler farkı istatistiksel olarak anlamlı çıkmıştır $(p<0.05)$. VMAT tedavi modeli ile ince bağırsak dozlarında düşüş elde edilirken ikinci derece kritik organ olan femur başları dozlarında belirgin bir artış görülmüştür. YART'de tedavi alanlarının gantri açılarının femur başlarından geçmemesinden kaynaklanıyor olabilir.

Büyük bir kısmı PTV içerisinde olan rektum ve mesane dozlarının karşılaştırmasında; rektumun 50 Gy doz alan hacim yüzdeliğinin YART tekniğindeki ortanca değeri \%25.73 iken, VMAT tekniğinde buna yakın olarak $\% 23.78$ değeri hesaplanmıştır $(p=0.646)$. Aynı şekilde mesanenin aynı doz değerinde YART tekniğinde ortanca değeri \%24.45 iken, VMAT tekniğinde \%26.53 olarak bulunmuştur ( $p=0.074)$. Rektum ve mesane için bulunan bütün değerler istatistiksel olarak anlamlı değildir ( $p>0.05)$.

Cozzi ve ark. (7) çalışmasında tedavi süreleri ve Gray başına MU karşılaştırmasında; VMAT tekniğinin daha avantajı olduğu sonucuna varılmıştır. Doz hızının ortalama $400 \mathrm{MU} / \mathrm{dk}$ olduğu çalışmada VMAT için ortalama 140 saniye tedavi süresi elde edilirken, doz hızının 200 ile 500 MU/dk arasında olduğu YART tekniğinde yaklaşık $15 \mathrm{dk}$ olarak belirlemişlerdir. Gray başına MU değerlerinde VMAT tekniğinde $245 \pm 17$
MU/Gy bulunurken, YART tekniğinde 479 463 MU/Gy sonucuna ulaşılmıştır. Rao ve ark. $(25,26)$ prostat, başboyun, akciğer kanseri hastalarında YART, VMAT, helikal tomoterapi plan karşılaştırmalarında, VMAT tedavi süreleri 2.1 ile $4.6 \mathrm{dk}$ arasında değişirken, YART metodunda 7.9 ile $11.1 \mathrm{dk}$ arasında değişerek VMAT'ın daha kısa tedavi süreleri sağladığını saptamışlardır. Yine aynı çalışmacıların 2010 yılında yaptığı plan kalitesi karşılaştırmasında, aynı geometride VMAT'ın \%18 daha kısa tedavi süreleri sağladığını saptamışlardır.

Çalışmamızda doz hızı, VMAT için en düşük değer 60 MU/dk seçilirken; YART için $400 \mathrm{MU} / \mathrm{dk}$ seçilerek tedavi planlarının yapılmasıyla elde edilen fraksiyon başına MU değerlerinde VMAT'deki ortanca değerin (776.8) YART tekniğindeki ortanca değere (621.9) göre daha yüksek olduğu sonucuna varılmıştır $(p=0.005)$. Kronometre yardımıyla ölçülen VMAT tekniğinin de tedavi süresi 9.51 dk iken, YART tekniğinde $14.26 \mathrm{dk}$ bulunarak VMAT'ın daha kısa tedavi süresi avantajına sahip olduğu belirlenmiştir $(p=0.005)$.

Cozzi ve ark. (7) çalışmasında, $10 \mathrm{~Gy}$ doz alan hacim yüzdeliğinin (integral doz) YART tekniğinde ortalama değerini \%32.0 \pm 3.3 , VMAT tekniğinde ise \%32.1 \pm 3.6 olarak saptamışlardır $(p=0.77)$. Çalışmamızda, sağlıklı dokuların 10 Gy doz alan hacim yüzdeliği, VMAT tekniği için ortanca 44.84 iken, YART tekniğinde ortanca 44.60 olarak belirlenmiş olup istatistiksel olarak fark yoktur $(p=0.575)$. Her iki tedavi modelinde de düşük doz alan sağlıklı dokuların olası ikincil kanser riski açısından benzer olduğu görülmüştür.

YART ve VMAT tedavileri için en önemli hususlardan biri de bu tedavilerin uygulanabilirliğidir. Bunu anlamanın en önemli yolu yapılacak olan dozimetrik ölçümler, yani kalite kontrol testleridir. Hastalardaki $1 \mathrm{~mm}$ 'lik pozisyon hatasının bile doz dağılımına etkisinin oldukça yüksek olduğu bilindiğine göre, bu testlerin önemi daha da artmaktadır. Tedavi için $\pm \% 3$ hata sınırlaması vardır. Bu sınırın üzerindeki hatalarda ya planlama baştan yapılmalı ya da hastanın bu tedavi için uygun olmadığına karar verilip, başka bir tedavi tekniği seçilmelidir. Yapılan bu çalışmada ölçülen dozun istenilen sınırlar ( $\leq \% 3)$ içinde olduğu saptanmıştır.

\section{Sonuç}

Hasta konforuna ve cihaz performansına etkileri bakımından tedavi süreleri kıyaslaması yapıldığında VMAT tekniğinde daha kısa süreler elde edilerek avantaj sağlanmaktadır. Sağlıklı dokuların olası ikincil kanser riski açısından değerlendirilmesinde her iki teknik arasındaki fark olmayıp kritik organlara verilen dozların RTOG 0418 raporunda verilen sınırlamaları aşmadığı görülmüştür. VMAT tekniğinin, YART tekniğine göre hem avantajlı hem de dezavantajlı tarafları olup, radyasyon onkolojisi kliniğinde var olan cihaz ve hastanın durumuna göre her iki tedavi modeli de kullanılabilir. 


\section{Kaynaklar}

1. Acun H, Kemikler G, Çakır A, Tuncay E, Ağaoğlu F, Darendeliler E. Statik IMRT (step and shoot) yöntemine göre oluşturulan IMRT planlarının dozimetrik doğrulanmasına segment sayısının etkisi. Türk Onkoloji Dergisi 2011;26(1):18-20.

2. Bar W, Alber M, Nüsslin F A variable fluence step clustering and segmentation algorithm for step and shoot IMRT. Phys Med Biol 2001;46(7):1997-2007.

3. Bedford JL, Lee YK, Wai P, South CP, Warrington AP. Evaluation of the Delta4 phantom for IMRT and VMAT verification. Phys Med Biol 2009;7;54(9):167-76.

4. Bedford JL, Warrington AP Commissioning of volumetric modulated arc therapy (VMAT). Int J Radiat Oncol Biol Phys 2009;73(2):537-45.

5. Beriwal S, Jain SK, Heron DE, de Andrade RS, Lin CJ, Kim H. Dosimetric and toxicity comparison between prone and supine position IMRT for endometrial cancer. Int J Radiat Oncol Biol Phys 2007;67(2):485-9.

6. Bortfeld T, Webb S. Single-Arc IMRT? Phys Med Biol 2009;7;54(1):9-20.

7. Cozzi L, Dinshaw KA, Shrivastava SK, et al. A treatment planning study comparing volumetric arc modulation with RapidArc and fixed field IMRT for cervix uteri radiotherapy. Radiother Oncol 2008;89(2):180-91.

8. Fippel, M. Fast Monte Carlo dose calculation for photon beams based on the VMC electron algorithm. Med Phys 1999;26(8):1466-75.

9. Fippel M, Haryanto F, Dohm O, Nüsslin F, Kriesen S. A virtual photon energy fluence model for Monte Carlo dose calculation. Med Phys 2003;30(3):301-11.

10. Fong, Y. Crumley, C. Planning feasibility study comparing 3DCRT, IMRT and RapidArc in patients with gynecological cancers. BC Cancer Agency 2004;22(5):166-78.

11. Grofsmid D, Dirkx M, Marijnissen H, Woudstra E, Heijmen B. Dosimetric validation of a commercial Monte Carlo based IMRT planning system. Med Phys 2010;37(2):540-9.

12. Jeleń $U$, Alber M A finite size pencil beam algorithm for IMRT dose optimization: Density corrections. Phys Med Biol 2007;7;52(3):617-33.

13. Jeleń U, Söhn M, Alber M. A finite size pencil beam for IMRT dose optimization. Phys Med Biol 2005;21;50(8):1747-66

14. Guo S, Ennis RD, Bhatia S, et al. Assessment of nodal target definition and dosimetry using three different techniques: Implications for re-defining the optimal pelvic field in endometrial cancer. Radiat Oncol 2010;27;5:59.

15. Kawrakow I, Fippel M. Investigation of variance reduction techniques for Monte Carlo photon dose calculation using XVMC. Phys Med Biol 2000;45(8):2163-83.

16. Khan, FM. The Physics of Radiation Therapy, $3^{\text {rd }}$ ed. Philadelphia; Lippincott Williams\&Wilkins 2014

17. Lim K, Small W Jr, Portelance L, et al. Gyn IMRT Consortium consensus guidelines for delineation of clinical target volume for intensity-modulated pelvic radiotherapy for the definitive treatment of cervix cancer. Int $\mathrm{J}$ Radiat Oncol Biol Phys 2011;1;79(2):348-55

18. McGary JE, Grant W 3rd, Woo SY, Butler EB. Reporting and analyzing dose distributions: A concept of equivalent uniform dose. Med Phys 1997;24(8):1323-4.

19. Monaco Traing Guide. Available from: https://tr.scribd.com/document/210743768/MonacoTrainingGuide.

20. Nakamura JL, Verhey LJ, Smith V, et al. Dose conformity of gamma knife radiosurgery and risk factors for complications. Int J Radiat Oncol Biol Phys 2001;1;51(5):1313-9.

21. Ozsaran Z, Yalman D, Yürüt V, et al. Lokal ileri evre serviks kanseri tanısı ile radyokemoterapi uygulanan olgularda erken sonuçlar. Ege Tıp Dergisi 2002, 41, (3), 157-62.

22. Park DH, Shin D, Park SY, et al. Optimized matching of film dosimetry with calculated doses for IMRT quality assurance. Phys Med 2007:23(2):49-57.

23. Report of the AAPM Task Group No. 105: Issues associated with clinical implementation of Monte Carlo-based photon and electron external beam treatment planning. Available from: https://www.aapm.org/pubs/reports/RPT_105.pdf

24. Rao M, Yang W, Chen F, et al. Comparison of elekta VMAT with helical tomotherapy and fixed field IMRT: Plan quality, delivery efficiency and accuracy. Med Phys 2010;37(3):1350-9.

25. Rao M, Cao D, et al. Comparison of anatomy-based, fluence-based and aperture-based treatment planning approaches for VMAT. Phys Med Biol 2010;7;55(21):6475-90.

26. Semenenko VA, Reitz B, Day E, Qi XS, Miften M, Li XA. Evaluation of a commercial biologically based IMRT treatment planning system. Med Phys 2008;35(12):5851-60.

27. The International Commission on Radiation Units and Measurements ICRU 83 Prescribing, recording, and reporting photonbeam intensity-modulated radiation therapy (IMRT). Available from: $h$ ttps://www.fnkv.cz/soubory/216/icru-83.pdf

28. Thieke C, Bortfeld T, Niemierko A, Nill S. From physical dose constraints to equivalent uniform dose constraints in inverse radiotherapy planning. Med Phys 2003;30(9):2332-9.

29. Verbakel WF, Senan S, Lagerwaard FJ, Cuijpers JP, Slotman BJ. Comments on 'Single-Arc IMRT?'. Phys Med Biol 2009;21;54(8):31-4.

30. Wu Q, Mohan R, Niemierko A, Schmidt-Ullrich R. Optimization of intendity modulated radiotheraphy plans based on the equivalent uniform dose Int J Radiat Oncol Biol Phys 2002; 1;52(1):224-35. 